\section{Controlled trial of medical treatment of active chronic otitis media}

Active chronic otitis media is a common condition affecting $0.6 \%$ of adults in the United Kingdom. Initial management is usually by general practitioners, who annually prescribe systemic and topical antibiotics on at least 178000 and 73000 occasions respectively (unpublished observations). Despite this there have been few studies of the efficacy of antibiotics, ${ }^{1-4}$ and no study has included a control group of untreated patients or of patients treated solely by aural toilet. We undertook a controlled study comparing appropriate systemic or topical antibiotic treatment with weekly aural toilet and insufflation of boric acid and iodine powder.

\section{Patients, methods, and results}

Seventy five patients aged over 16 with active chronic otitis media and without cholesteatoma or aural polyp were allocated randomly to one of three treatment regimens for four weeks. One group received aural toilet weekly by an otologist, who used microscopic vision and suction aspiration when necessary, followed by insufflation of boric acid and iodine powder. The second group received oral systemic antibiotics-namely, cephalexin, flucloxacillin, cloxacillin, or amoxycillin 1-2 g/day. The third group received topical aural antibiotics without steroids-namely, gentamicin (Genticin) three or four drops four times a day or chloramphenicol (Chloromycetin) one or two drops three times a day. The choice of antibiotic depended on the in vitro sensitivity of the aerobic flora isolated from the ear discharge the previous week. Because Pseudomonas spp are inherently resistant to oral antibiotics patients from whom they were isolated were randomly allocated to receive either aural toilet or topical antibiotics.

The allocation to treatment regimen was kept blind from the clinicians, with the necessary exception of aural toilet. All medication was supplied in the clinic. Patients were considered to be non-compliers if less than $75 \%$ of the medication was used. The efficacy of treatment was assessed after four weeks, when the ears were classified as showing active, mucoid, or inactive disease.

Efficacy of four weeks of treatment in 51 patients with chronic otitis media. (No from whom Pseudomonas spp were isolated before treatment given in parentheses)

\begin{tabular}{|c|c|c|c|c|}
\hline \multirow{2}{*}{ Treatment } & \multirow{2}{*}{$\begin{array}{c}\text { No of } \\
\text { patients }\end{array}$} & \multicolumn{3}{|c|}{ State of disease } \\
\hline & & Active & Mucoid & Inactive \\
\hline $\begin{array}{l}\text { Aural toilet } \\
\text { Systemic antibiotic } \\
\text { Topical antibiotic }\end{array}$ & $\begin{array}{ll}20 & (7) \\
13 & \\
18 & (3)\end{array}$ & $\begin{array}{rr}5 & (2) \\
8 & \\
11 & (1)\end{array}$ & $\begin{array}{ll}8 & (3) \\
4 & (2)\end{array}$ & $\begin{array}{ll}7 & (2) \\
5 & \\
3 & \end{array}$ \\
\hline Total & $51(10)$ & $24(3)$ & $12(5)$ & $15(2)$ \\
\hline
\end{tabular}

Of the 75 patients, 24 were defaulters or non-compliers. The table shows that the disease became inactive in only $15(29 \%)$ of the 51 patients who complied with treatment. Four $(21 \%)$ of the 19 patients who previously had undergone modified radical mastoidectomy showed inactive disease. No significant difference in results was observed between any drugs or groups of patients.

\section{Comment}

The extremely poor results obtained with all three forms of treatment are disappointing and contrast strongly with the reported success rates in non-controlled studies of $80-92 \%$ with topical gentamicin $^{12}$ and $92 \%$ with topical chloramphenicol. ${ }^{3}$ We are unaware of any study reporting the use of topical steroids. The only systemic antibiotic that has been reported is clindamycin, which had a success rate of $30 \%$.

This study might be criticised because of the relatively small number of patients. The $95 \%$ confidence limits suggest that if more patients had been studied a $60 \%$ response rate might have been achieved. Larger numbers have received similar management in the same department, albeit without randomisation, with similar results. We decided to investigate potentially more effective forms of treatment rather than to extend this study to show significant differences between treatments, the best of which might have had only a $60 \%$ success rate.

Why do antibiotics fail ? Possibly our patients, because they were secondary referrals, had more serious disease than those in other series, but the natural resolution rate in less severe disease would be higher than in our study. The success of topical antibiotics in only two of seven patients with a modified radical cavity suggests that failure of antibiotics is not just a matter of access.

An alternative explanation might be that chronic otitis media is not primarily a bacterial infection. Opportunistic pathogens may be isolated from half of ears with inactive disease (unpublished observations), which indicates that they may be secondary invaders of inflamed mucosa caused by other, as yet undefined, processes.

In conclusion, there is no firm evidence to support the use of systemic antibiotics or topical antibiotics without steroids in active chronic otitis media.

1 Tambie B, Tambie $T$. Treatment of purulent otorrhoea with special reference to otitis media. Clinical Trials fournal 1976;13:129-36.

${ }^{2}$ Gyde MC. When the weeping stopped. Arch Otolaryngol 1976;102:542-6.

${ }^{3}$ Fox FG. Suction combined with chemotherapy in purulent otitis media: a report of 76 cases. Eye, Ear, Nose and Throat Monthly $1964 ; 43: 48-51$.

4 Kambata AS. Treatment of chronic discharging ears with clindamycin. Clinical Trials fournal $1972 ; 6: 20-21$.

- Browning GG, Picozzi GL, Sweeney G, Calder IT. Role of anaerobes in chronic otitis media. Clin Otolaryngol 1983;8:47-51.

(Accepted 1 fune 1983)

\section{Glasgow Royal Infirmary, Glasgow G4 OSF}

G G BROWNING, MD, FRCS, consultant, department of otolaryngology

G L PICOZZI, MB, FRCS, senior registrar in otolaryngology, Glasgow rotation scheme

I T CALDER, MSC, MPS, staff pharmacist, pharmacy department

G SWEENEY, BSC, PHD, bacteriologist, department of bacteriology

Correspondence to: Mr G G Browning.

\section{Pulmonary hypertension in systemic lupus erythematosus}

Pulmonary hypertension has hitherto been reported rarely in systemic lupus erythematosus. We report on six patients with this condition seen recently at this hospital. None of them showed evidence of parenchymal lung disease considered to be sufficient to cause pulmonary hypertension, and none had overt pulmonary thromboembolism.

\section{Patients, methods, and results}

Six patients with systemic lupus erythematosus presented at this hospital with pulmonary hypertension. This had developed up to 29 years after the onset of symptoms of systemic lupus erythematosus. We did not identify parenchymal lung disease sufficient to cause pulmonary hypertension in any of them, and none showed evidence of pulmonary embolism. Five were found to have circulating lupus anticoagulant, an antibody associated with tendency to widespread, in situ thrombosis. Two (cases 2 and 6 ) had histories of venous thrombotic episodes elsewhere. All patients showed immune complexes as measured by $\mathrm{Clq}$ binding assay. We noted other symptoms thought to be associated with the pathogenesis of pulmonary hypertension (table)

\section{Comment}

Pulmonary hypertension is well recognised in certain connective tissue diseases, particularly scleroderma, but its occurrence in systemic lupus erythematosus has been infrequently reported. ${ }^{1}$ Its aetiology is not clear. Possible factors in its pathogenesis are vasospasm, arteritis, platelet dysfunction, and thromboembolism. A link between pulmonary hypertension, Raynaud's phenomenon, and connective tissue disease was suggested by Walcott et al, ${ }^{2}$ who described a series of 23 patients with pulmonary hypertension, seven of whom suffered from Raynaud's phenomenon and three from arthritis. Arthritis has been noted by other workers together with a family history of arthritis and Raynaud's phenomenon in patients with pulmonary hypertension. Raynaud's phenomenon has often been present in the cases of pulmonary hypertension with systemic lupus erythematosus reported to date. Three of our patients 